\title{
Dialogia
}

e-ISSN: 1983-9294

\section{Violência e educação: sensibilização por meio da cinematografia}

Violence and education: sensitization through cinematography

Adilson Cristiano Habowski

Mestrando em Educação na Universidade La Salle, Canoas - RS, Brasil. Bolsista CAPES/PROSUC. Participante do Núcleo de Estudos sobre Tecnologias na Educação NETE/UNILASALLE/CNPq. adilsonhabowski@hotmail.com

Elaine Conte

Doutora em Educação pela Universidade Federal do Rio Grande do Sul. Professora da Universidade La Salle no Programa de Pós-Graduação em Educação, Canoas - RS, Brasil. Líder do Núcleo de Estudos sobre Tecnologias na Educação - NETE/UNILASALLE/CNPq. elaine.conte@unilasalle.edu.br

\section{Raul Maia de Andrade Neves Neto}

Doutor em Educação pela Universidade La Salle. Professor no Ensino Fundamental da Secretaria Municipal de Educação da Prefeitura Municipal de Cachoeirinha - RS, Brasil. Participante do Núcleo de Estudos sobre Tecnologias na Educação -

NETE/UNILASALLE/CNPq. yahaul@yahoo.com.br

Resumo: Tecer uma compreensão hermenêutica acerca da violência e suas interfaces com a educação não é uma tarefa fácil. Para tanto, a investigação propõe debater a questão da violência, tendo por base as discussões criadoras de Theodor Adorno e as potencialidades da cinematografia, que apresenta a violência escolar em relação às diferenças e à diversidade cultural. Será que a verdadeira luta contra a violência exige sua validez tematizada e colocada sob condições epistêmicas para o reconhecimento intersubjetivo na sala de aula? Concluímos que a escola precisa apropriar-se do saber epistêmico para lutar contra a exclusão e reprimir as formas de violência escolar e barbáries cotidianas, estabelecendo diálogos voltados para a sensibilidade humana em suas interfaces pedagógicas. A obra cinematográfica oferece possibilidades para novos entendimentos que podem ser reconstruídos em diferentes contextos, bem como lança questões sensíveis que surgem como inquietações para aprender a pensar sobre as violências escolares.

Palavras-chave: Educação. Violência. Cinematografia.

\begin{abstract}
Weaving a hermeneutical understanding of violence and its interfaces with education is not an easy task. To this end, the research proposes to debate the issue of violence, based on the creative discussions of Theodor Adorno and the potential of cinematography, which presents school violence in relation to differences and cultural diversity. Does the true struggle against violence require its thematized validity and placed under epistemic conditions for intersubjective recognition in the classroom? We conclude that the school needs to appropriate epistemic knowledge to fight exclusion and repress forms of school violence and everyday barbarism, establishing dialogues focused on human sensitivity in its pedagogical interfaces. The cinematographic work offers possibilities for new understandings that can be reconstructed in different contexts, as well as launches sensitive issues that arise as concerns to learn to think about school violence.
\end{abstract}

Keywords: Education. Violence. Cinematography. 


\section{Introdução}

Compreende-se por violência neste estudo o descaso, omissão ou negligência da sociedade, controlada por relações de poder e inscrita na exploração da força do trabalho, da conservação ou controle dos meios de produção e distribuição da riqueza. Destacamos ainda que a violência simbólica causa danos psicológicos e morais (patologias sociais), sendo exercida sem coação física (BOURDIEU, 1989). Trata-se de um processo automático, impensado e reificado da máquina que faz lembrar os instintos sociais mais primitivos, mas que se configura em um dos grandes desafios para o ambiente escolar, sobretudo, quando se verifica que com os aperfeiçoamentos tecnológicos não se construiu possibilidades de estagnar a violência, a barbárie humana, o jogo e o poder da força física e da insensibilidade que se reproduz de modo recorrente na história da humanidade. Ao contrário, a formação sem resistência crítica e a cultura sem a tensão constitutiva (de submeter-se sem perder a autonomia) passou a ser uma forma de adaptação da vida instrumentalizada e a serviço da situação ou sistema vigente (HABOWSKI; CONTE; FLORES, 2018). Nesse domínio administrado da vida, os sujeitos vão se tornando frios e insensíveis ao sofrimento dos outros (ADORNO, 1995).

Os contextos de violência demandam resistências das esferas públicas, principalmente das instituições de ensino que trazem na sua envergadura os limites e as possibilidades dos processos formativos. A escola, pela sua dimensão reflexiva para problematizar a realidade no processo educacional em vista da transformação humana, precisa proporcionar um pensar e agir pela coexistência dialógica das diferenças humanas e as experiências subjetivas. O conhecimento da cinematografia no contexto escolar vai ao encontro da produção cultural, pois nestas produções estão subjacentes uma diversidade de sentidos e significados da formação, da experiência intelectual, das questões sociais, políticas, econômicas, ideológicas e educativas da vida em sociedade. Nessa metamorfose cultural, a cinematografia se justifica pela potencialidade para pensar as relações pedagógicas e os modos de agir socioeducacional, quando estamos mergulhados na dor e na incapacidade da experiência formativa devido à reificação dos sentidos e à frieza edificada pela razão instrumental, de autolegislação das situações de violência e discriminação das diferenças.

Diante disso, perguntamos: quais elementos Theodor Adorno oferece para pensarmos uma educação que potencialize processos formativos que não sejam indiferentes a ações de violência e barbárie humana? De que forma podemos desenvolver a sensibilidade humana na escola por meio da cinematografia? A cinematografia abre caminhos de 
(re)conhecimento sensível do diferente, colaborando para a emergência dos debates e das contradições formativas (pela capacidade de se colocar no lugar do outro e por apresentar linguagens ambíguas de concepções de mundo, de conhecimentos e questões de identidade social), de resistência ao conformismo, pois rompe com os preconceitos culturais que aniquilam e segregam as diferenças. A pesquisa tem alicerce na abordagem hermenêutica reconstrutiva que nos permite a abertura à conversação e à revisão das interpretações humanas, buscando um diálogo vivo com as tradições formativas, para (re)pensar as dimensões da vida problemática (com atos de violência) em sociedade (HABERMAS, 1990).

\section{Adorno: inter-relações entre educação, violência e barbárie}

A partir das experiências com o exílio, por ocasião da Segunda Guerra Mundial, contexto em que o totalitarismo nazista conduziu a sociedade alemã à submissão diante de um ditador, Adorno compreende que precisamos resistir e reprimir atos de barbárie, para não recair na mesma visão distorcida e limitada a uma raça pura, que foi marcada pelo sofrimento humano e indiferença em relação ao outro. Adorno (1995) manifesta em suas obras o poder da educação autocrítica para conduzir ao esclarecimento das informações e à emancipação coletiva para que a barbárie não volte a se repetir, sendo a reeducação o último reduto diante do império da Indústria Cultural. Adorno e Horkheimer (1985) afirmam que a sociedade desenvolveu grandes tecnologias, entretanto, a humanização se tornou cada vez mais fragilizada. Adorno (1995, p. 155) esclarece que a barbárie pode tornar a acontecer, por uma agressividade ou ódio primitivo, que caracteriza a tendência imanente da (anti)civilização, mesmo "estando na civilização do mais alto desenvolvimento tecnológico, as pessoas se encontrem atrasadas de um modo peculiarmente disforme em relação a sua própria civilização".

Adorno (1995) compreende que com a coisificação dos sujeitos, a violência se tornou banalizada ao equipar o ser humano como coisa instrumentalizada, causando a perda do sentido ou encontro intersubjetivo, do valor altruísta de identificação e relação com o outro. A coisificação do sujeito evidenciada no Holocausto conduziu a humanidade à deterioração, mas serve de retrovisor para que não seja esquecida, tornando-se um ponto de análise para que esse tipo de atrocidade seja repensado e sirva de resistência autocrítica. Auschwitz fica registrada na história da (des)humanidade pelo retrocesso dominado pela frieza, brutalidade, repressão e indiferença ao outro, predicados dos campos de concentração. Para que Auschwitz. não se repita, Adorno (1995) entende que a saída reside no esclarecimento das consciências, 
sendo uma conduta orientada pela luta sócio-educacional que inicia por uma educação das massas.

Adorno (1995) oferece elementos para elucidar o fracasso da humanização da civilização a nível reflexivo, da generalização da alienação e da dissolução da experiência formativa. Um povo civilizado permite Auschwitz pelo exercício autoritário e pelo não reconhecimento intersubjetivo das diferenças, que impede a confiança e o diálogo de identificação coletivo, construído pelos mecanismos de anticivilização, poder manipulador de homogeneizar o coletivo. Sujeitos que se moldam cegamente em coletivos convertem a si próprios em dependentes de uma autoridade exterior de caráter manipulador da consciência coisificada, ou seja, "no começo as pessoas deste tipo se tornam por assim dizer iguais a coisas. Em seguida, na medida em que o conseguem, tornam os outros iguais a coisas” (ADORNO, 1995, p. 130).

$\mathrm{Na}$ relação atual com a técnica, os sujeitos ao mesmo tempo em que progridem podem regredir num irracionalismo patogênico. Adorno (1995) reitera que a ideia de Auschwitz não se repita é primordial, o que torna a educação essencial para trabalhar com a inconsciência dessa agressividade, a partir da problematização do existente. Theodor Adorno (1995) afirma que a educação precisa trabalhar questões essenciais para não recair na barbárie humana, que começa pelos diálogos com a Educação Infantil e que repercute na vida em sociedade, despertando um ambiente e sensação social libertador, intelectual e cultural da produção de uma consciência verdadeira. Por isso, defende que é preciso redobrar a atenção com o processo formativo das crianças, para torná-las desde a primeira infância menos violentas e com capacidade para canalizar a pulsão da agressividade em ações culturais. Adorno (1995) propõe a reflexão crítica dos sujeitos sobre seu próprio contexto, identificando os mecanismos subjetivos da violência como parte da razão instrumental, administrada, que age inclusive no inconsciente das pessoas.

A carência de sentidos para a prática intersubjetiva de reconhecimento recíproco na cultura direciona para barbáries coletivas e para a falta de investimento nos bens culturais. Os conteúdos, "teimosamente repetidos, ocos e já em parte abandonados" fornecem espaço para as inovações sem sentido, quando podem fascinar a massa através dos efeitos imediatos, mantendo o encantamento, fazendo com que os sujeitos continuem estimulados para suportar o próprio vazio repetitivo que já o estava incomodando (ADORNO; HORKHEIMER, 1985, p. 112). Cria-se um sistema capitalista de juízo próprio, de par com as relações isoladas e vinculado a uma barbárie monológica da indústria da cultura, de forma 
que ninguém possa se encontrar com o outro, bloqueando as possibilidades de transcender a própria cultura, prejudicando a autonomia e o diálogo cultural.

A autocompreensão coletiva por meio da educação desvela uma perspectiva inclusiva, de uma pessoa que se qualifica como um nós competente, voltada para a formação cultural da qual nos projetamos como sujeitos com potencialidade ao exercício da autonomia, capazes de linguagem e ação na força do agir comunicativo para nossas atitudes, comportamentos e realizações (HABERMAS, 2002). O sistema escolar precisa ultrapassar as tendências homogeneizadoras da dominação capitalista, apontando para a perspectiva sociológica da escola enquanto instituição social capaz de formar o sujeito de responsabilidade e autocompreensão da prática cotidiana de dar e exigir razões, criando condições para libertá-lo dos enlaces da dominação inerentes à ordem social. Para Adorno (1995), a educação é libertadora e implica a emancipação do pensamento coletivo quando se comunica com o mundo vigente, pois abre outros caminhos à reconstrução de conhecimentos, a partir da resistência aos mecanismos de controle, que endossam a (re)produção do desprezo social. Adorno (1995) faz uma relação entre educação, barbárie e violência humana, tendo em vista que no sujeito está latente o impulso de agressividade decorrente da coerção da vida em sociedade. Mas o saber da educação coloca a capacidade revisora dos processos de aprendizagem no mundo como possibilidade de reeducar os sujeitos, de modo que a agressividade não vire hábito e seja confrontada com a autoridade deste costume, em direção ao outro. A educação precisa justificar-se na capacidade de participação social, visto que com o desenvolvimento e aprimoramento tecnológico a humanidade ainda exerce a barbárie humana (ADORNO, 1995). Com isso, "é necessário contrapor-se a uma tal ausência de consciência, é preciso evitar que as pessoas golpeiem para todos os lados sem refletir a respeito de si próprias. A educação tem sentido unicamente como educação dirigida a uma autorreflexão crítica" (ADORNO, 1995, p. 121). Fundamentalmente,

A barbárie desenvolve-se quando não reconhecemos o ser humano como aventura singular e coletiva, quando tratamos como objeto, máquina, computador ou fantoche religioso ou ideológico esse extraordinário organismo biopsicocultural e histórico que um ser humano é. O antônimo de barbárie é educação, com os valores de solidariedade e de dignidade que possibilitam a aventura humana, nas suas formas universais, culturais e singulares. (CHARLOT, 2019, p. 178).

Entretanto, a sociedade que poderia proporcionar princípios para o desenvolvimento do esclarecimento geral, da (auto)crítica e da autonomia dos sujeitos, tem servido ao capital, causando a semiformação. Quando a educação é dominada pelos dispositivos de preservação 
dos princípios capitalistas, gera-se a violência simbólica, o sujeito é coisificado, discriminado e tornado vulnerável por preconceitos e exclusões de (re)conhecimento, tendo inclusive seus direitos humanos, educacionais e sociais violados. A sociedade semiformada reflete a passividade e o deslocamento de falsas verdades em formas de vida massificadoras e de legitimação da ignorância em ação, promovidas pela homogeneização das controvérsias da indústria cultural.

Quanto mais vulneráveis e suscetíveis estamos diante dessas transformações, mais precisamos confrontar os saberes e as práticas sociais de educar. Uma apropriação críticoreflexiva do patrimônio cultural depende de uma abordagem educativa voltada para a luta por reconhecimento social e contestação de ideologias dominantes que insinuam a neutralidade técnica. Isso nos faz pensar na falta de esclarecimento geral da sociedade e no quanto somos corresponsáveis pelos atrasos formativos e pelos problemas de violência, agressão e exclusão da atualidade. É nesse contexto que "a educação seria impotente se ignorasse a adaptação e não preparasse os homens para se orientarem no mundo. Porém seria questionável igualmente se ficasse nisto, produzindo nada além de well adjusted people, em consequência do que a situação existente se impõe no que tem de pior" (ADORNO, 1995, p. 143).

Segundo Horkheimer (1991, p. 45-46), “o pensamento crítico é motivado pela tentativa de superar a tensão, de eliminar a oposição entre a consciência dos objetivos, espontaneidade e racionalidade, inerentes ao indivíduo, de um lado, e as relações do processo de trabalho, básicas para a sociedade, de outro". A educação tem esse papel político de resistência e de denúncia dos barbarismos com a exploração, desumanização, reprodução de valores distorcidos, manipulação social e miserabilidade proveniente de violações socioculturais. Compreende-se, com Adorno (1995), que a educação é uma experiência de reeducação da sociedade administrada e coisificada. Sem a capacidade de autorreflexão crítica, estamos presos a essa (re)produção capitalista totalitária, que dita modos de vida por inovações e progressos antidemocráticos, realizando uma sedução e semiformação coletiva, inibindo as possibilidades de reação para as próprias coisas aí tratadas. A educação implica na possibilidade de conferir novos sentidos intersubjetivamente partilhados e significados aos sujeitos no entrelaçamento de percursos, para resistir à modelagem de pessoas e a mera transmissão de conteúdos apassivados e conformistas.

A suposição de Adorno (1996, p. 10) é que a semicultura está associada à semiformação, e a educação ajuda a desenvolver a formação cultural e potencializa as análises críticas da própria experiência, pois, “a formação que se esquece disso, que descansa em si 
mesma e se absolutiza, acaba por converter-se em semiformação". "A semiformação é o espírito conquistado pelo caráter de fetiche da mercadoria", dificultando uma formação que conduza à compreensão e à percepção de sua condição social de dominados, sendo incapazes de questionar a própria (semi)formação adquirida (ADORNO, 1996, p. 25). A uniformização da realidade conduz a um empobrecimento do pensar e a insensibilidade em relação ao outro e aos dispositivos que disseminam as estruturas institucionalizadas de violência e injustiça social, que dominam o status quo e pregam a indiferença frente às barbáries coletivas.

A educação emancipadora ocupa posição contrária aos princípios objetivistas e que exercem a violência e a barbárie em relação ao outro. Por exemplo, Freud (1930) assemelha a educação aos processos de renúncia dos instintos primitivos, uma tensão entre os impulsos subjetivos e os princípios de convívio intersubjetivo. No processo de civilização, quando aprendemos sobre os princípios normativos para o bem comum, somos convidados a exercer a cidadania, por meio de direitos e deveres, e a renunciar os desejos egoístas e possessivos em relação ao outro, que são socialmente inconcebíveis (FREUD, 1930). A educação surge como forma de auxiliar o sujeito na ambivalente tensão de administrar as próprias divergências subjetivas para ser aceito pela sociedade com seus princípios, mas regulando os impulsos agressivos, pois Freud (1930) entende como algo constitutivo do ser humano e do próprio núcleo sócio-cultural.

$\mathrm{Na}$ verdade, a ambiguidade entre desejo e repressão é motivadora de violência, e a educação precisa encontrar meios para assimilar e regular os impulsos agressivos. Assim, o processo educativo não pode desconhecer o sujeito de contradição e incompletude, em suas formas de ser e agir no mundo de ambivalências, que precisam ser debatidas nos processos formativos com os professores e estudantes. Nessa perspectiva, a educação se encontra como a coordenadora da tradição histórica e da formação cultural sobre os princípios de diálogo para a convivência, em detrimento dos instintos de violência, por meio de debates, produções artísticas que vão ao encontro do potencial educativo das relações comunicativas e solidárias.

A intuição é de que o sistema social educa de maneira cada vez mais técnica os sujeitos para que sejam capazes de dar conta das demandas de produção com a posse e consumo dos desejos fabricados. Quando a racionalidade instrumental da ciência e da técnica adentra nos âmbitos institucionais de uma sociedade, ela é capaz de transformar decisões racionais em uma situação de aprendizagem fingida, ou seja, calcada na administração total de comportamentos na convergência da objetividade. Nesse cenário de conjuntura paradoxal, o aperfeiçoamento técnico, ao invés de emancipar os sujeitos, intensificou a submissão ao trabalho de tempo integral. Para sustentar a concorrência e aumentar 
vantagens, os serviços capitalistas acentuaram os padrões de produção dirigida simbolicamente para o outro, diminuindo o número de trabalhadores e aumentando o tempo de trabalho (assim como acontece com os professores em turmas numerosas), levando à hiperexploração daqueles que têm a sorte de se manter na euforia da produção.

Sem dúvida, perpetua-se de forma acelerada a mecanicidade do sujeito e o distanciamento intencional em relação ao mundo, sendo simples reprodutor de informações viabilizadas pela tecnociência, através do impulso solucionador feito para os objetos. Evidente que os objetos experimentados com a técnica são importantes, mas não bastam por si, pois demandam reflexão do próprio mundo para mais esclarecimentos em concordância com a emancipação coletiva. De acordo com Habermas (2002, p. 80), “sem uma suposição de racionalidade recíproca, não encontraríamos nenhuma base de entendimento suficientemente geral [...]". Quando não existe o reconhecimento das próprias normas existe a frieza e a relação de indiferença o que automaticamente intensifica a violência. Isso porque quando o outro passa a ser enxergado como coisa, o sofrimento dele não causa estranhamento e não limita os padrões de refutação ou do silêncio com a aceitação da violência (ADORNO, 1995).

A experiência formativa pela reeducação dos processos de socialização e de singularização é um "direito de aprender para ser, para apropriar-se de uma parte do patrimônio legado pelas gerações humanas precedentes, para tornar-se membro de uma sociedade (desigual) de uma cultura, para construir-se como sujeito insubstituível" (CHARLOT, 2013, p. 49). Nesse mundo hiperestimulado e globalizado, o sujeito acaba utilizando a técnica como uma prática inconsciente de desidentificação com o outro e os relacionamentos cada vez mais distanciados são marcados pelo isolamento (ADORNO, 1995). Ambas as questões de moldes mentalistas caracterizadas pela frieza e indiferença em relação aos outros automaticamente intensifica a violência e a falta de diálogo. Isso porque quando o outro passa a ser enxergado como objeto e representação, o sofrimento dele não causa estranhamento, sob o aspecto das vozes excluídas ou marginalizadas, perpetuando o silêncio com a violência alheia (ADORNO, 1995).

\section{Violência e educação: sensibilizando por meio da cinematografia}

Certamente, debater as obras filmicas fornece o entrecruzamento de diferentes áreas do conhecimento, de valores políticos, éticos e estéticos de experiências oriundas da tradição sóciocultural e de pressupostos pragmáticos determinados. A cinematografia na escola permite que as 
informações sejam verbalizadas e ponderadas, que a exclusão/inclusão/preconceitos de validez controversa tenham chance de ser debatidas e revisadas no encontro sensível do diálogo cultural capaz de problematizá-las, já que englobam os sentidos da experiência humana e suas contradições. À vista disso, Benjamin (1994, p. 174) considera que a democratização da produção cinematográfica é uma tendência de dimensão emancipadora que "serve para exercitar o homem nas novas percepções e reações exigidas por um aparelho técnico cujo papel cresce cada vez mais em sua vida cotidiana". As imagens cinematográficas trabalhadas em sala de aula oferecem direitos comunicativos iguais, pois a todos os participantes são dadas condições de se expressar sobre o filme e motivação à argumentação para publicizar enganos, exclusões e ilusões consideradas pela trama empírica. Então, "fazer do gigantesco aparelho técnico do nosso tempo o objeto das inervações humanas - é essa a tarefa histórica cuja realização dá ao cinema o seu verdadeiro sentido" (BENJAMIN, 1994, p. 174).

O uso expressivo da compreensão fílmica de mundos, também é problematizada por Morettin (2007, p. 53) ao afirmar que "a crítica analítica de uma obra cinematográfica de ficção deve se ater: à sociedade que a produz; à própria obra; à relação entre autor, filme e sociedade; à sua história (as várias versões que teve as suas recepções por parte da crítica, do público, etc.)”. É necessário desvendar as ideologias e superar a barbárie frente às enganações do mundo, pois essas produções não podem ser analisadas "como ponto de cristalização de uma determinada via, repositório inerte de várias confluências, sendo fílmico antecipado pelo estudo erudito" (MORETTIN, 2007, p. 63). Ainda, conforme Morettin (2007, p. 64), "se não conseguirmos identificar, através da análise fílmica o discurso da obra cinematográfica constrói sobre a sociedade na qual se insere, apontando para suas ambiguidades, incertezas e tensões, o cinema perde a sua efetiva dimensão de fonte histórica".

Nessa perspectiva, o assunto da violência requer uma postura de comprometimento do educador, a fim de promover a discussão com o mundo objetivo e social e a construção de uma ética fundada no respeito e no reconhecimento do outro, necessário para a convivência sócio-educacional e a compreensão de um sistema de referência mais amplo. Exemplo desse debate é o filme Extraordinário', recém-lançado no Brasil, que mostra um garoto que nasceu com uma deformação facial e aos 10 anos enfrenta, pela primeira vez, o contato com uma escola regular, com crianças preconceituosas em relação a sua aparência. O personagem é encantador aos olhos dos professores da classe, mas sua condição física gera angústias, descobertas e momentos de ironia vividos na escola, onde se tem a sensação constante de ser sempre vigiado e avaliado por todos à sua volta. Daí se esclarece a sensação de exclusão vivida pelo estudante na inclusão escolar, um enfemismo cruel, como diria Paulo Freire. Ao longo do filme, a criança (Auggie Pullman) sofre bullying dos colegas pela sua condição de ter uma deformidade facial que o torna estranho frente aos padrões

\footnotetext{
${ }^{1}$ EXTRAORDINÁRIO. Original: Wonder. Direção: Stephen Chbosky. 113 min. EUA, Paris Filmes, 2017.
} 
normais/convencionais, provocando afastamento e medo nos colegas. Em uma das cenas, o diretor da escola chama a família de uma das crianças que praticou o bullying, na tentativa de reprimir e neutralizar tal prática, evitando assim a legitimação dessa violência na escola. Em tais jogos de linguagem normativos da cena, os atores desvelam o bullying como uma expressão arraigada no âmbito social, visto que a mãe da criança chamada para dar explicações sobre a participação na (re)montagem da foto da turma, na qual exclui o colega, não reconhece seu erro, enquanto que o próprio filho pede desculpas ao diretor da instituição.

Nesse contexto, a contingência de violência é dilatada, pois um sujeito que perde a sensibilidade e o respeito humanizador acaba por perder o princípio da alteridade, de olhar, de se identificar e de se colocar no lugar do outro, na condição de aprendente. (HABOWSKI; CONTE; BRANCO, 2018). Por isso, o papel importante do educador para o esclarecimento dessas problemáticas do cotidiano escolar, e simultaneamente como um caminho aberto para reconhecer o potencial dos filmes, situados no mundo da vida, como um meio ao aprender evolutivo, que auxilie em novas formas de ver, pensar e agir na vida em sociedade. Esse tipo de prática de argumentação é necessário para o desenvolvimento de uma ação pedagógica que propicie o potencial de réplica, do debate conjunto ao desenvolvimento da criticidade, da arte da conversação, da contradição e da controvérsia cinematográfica, a fim de estimular uma nova postura diante da violência retratada. Ao problematizar a sociedade por meio da cinematografia, cria-se novos entendimentos em relação às barbáries sociais e escolares, evitando posturas violentas e comportamentos de dessensibilização coletiva.

Os limites dos mundos da vida particulares são estendidos pelo cinema que atinge o imaginário e as perturbações sociais, através da fusão de horizontes da comunicação no contexto do ensino e da aprendizagem. Nessa dimensão, a cinematografia desperta nossos sentimentos, arranjos sociais, emoções e pensamentos, por meio das imagens e tendências impregnadas nessa arte. Além disso, ela estimula nossa curiosidade epistemológica, assim como nos revela outras perspectivas de olhar as questões cotidianas, problematizando ações naturalizadas pela educação. Da perspectiva dos sujeitos participantes, tais leituras dos conhecimentos por meio do filme estranhamente ganham um caráter contraditório na leitura de acontecimentos e na execução do agir, iniciando pelo ato de duvidar, questionar, para não silenciar o injustificável ou recair ingenuamente na alienação coletiva de barbáries.

O filme Extraordinário na ação pedagógica mostra os sentidos complexos do ser humano no mundo e de como agimos, interligando sensibilidade, racionalidade e entendimento, através de uma correlação de discursos motivada para o agir fluido de 
percepções e de novas contradições da arte de educar. A intencionalidade pedagógica de usar o filme como dinâmica relacional e interdisciplinar de conteúdos no processo de ensino e de pesquisa autocorretiva traz à tona ideias de conhecimento e de juízos de experiência na prática. Para a garantia dos referentes semânticos, é imprescindível o cuidado na escolha do filme para reconhecimento interpretativo e formativo em torno da realidade. Evidentemente, o filme possibilita aos estudantes a identificação de temáticas, o encontro com a arte, as ideologias e os valores implicados nessa obra, bem como uma avaliação crítica sobre o assunto assistido em suas inter-relações, indo além de uma produção que embrutece tais sentidos.

As verificações dos fatos fílmicos e as referências possíveis dessa comunicação sobre algo no mundo convergem com a prática no mundo. "A chance de um filme se tornar um produto emancipado reside no esforço de se romper com esse nós, isto é, com o caráter coletivo a priori (inconsciente e irracional) e colocá-lo a serviço da intenção iluminista: autorreflexão crítica sobre si mesmo" (LOUREIRO, 2008, p. 145). Explorar a obra fílmica na educação joga com nosso acesso ao agir solucionador de problemas vividos para a formação de leitores críticos, a partir da reflexão humana, à (re)criação da própria cultura, uma vez que o artefato pode ser identificado como um documento de exame ético e estético, que representa valores, costumes e crenças, bem como uma complexidade ideológica de representação do campo social, cuja linguagem revela também os saberes pedagógicos. Com isso, explanar a cinematografia em tela na escola vai ao encontro da cultura eminente, pois as (re)produções fílmicas se encontram em arenas que são capazes de replicar, compilar uma multiplicidade de significados de valores e sentidos sócio-culturais. Em todo caso, os filmes com suas linguagens, imagens e sons proporcionam uma pluralidade de associações e atividades educativas, tornando-se um meio à (re)construção da criticidade no processo de formação destas correlações ontológicas e históricas, a partir da observação da vida social no agir comunicativo, para a suspensão de barbáries advindas da repetição impensada.

\section{Considerações finais}

Theodor Adorno coloca a educação como meio para desbarbarizar a sociedade, tendo sua plenitude quando orientada pelo diálogo autocrítico, de modo que a educação trabalhe a razão dessa agressividade, evidenciando os dispositivos autoritários, a partir da (auto)reflexão e da problematização dos motivos da violência. A racionalidade não é uma obrigação, mas implica saber e agir por bons motivos, manifestando uma sensibilidade atenta e crítico-reflexiva para resistir à disseminação de exclusões e violências, enquanto modo de gerar novas compreensões de mundo, de experiências humanizadoras e agregadoras de 
sentido à prática social. A educação enquanto um ato político, ético e estético precisa viabilizar os debates sobre as ações que geram violência, para fazer respeitar e valorizar as diferenças humanas e o diálogo com as experiências de um mundo da vida intersubjetivamente partilhado. Podemos ultrapassar reflexivamente nossas posições violentas nas diferentes formas de aprender com o outro, superando qualquer tipo de violência do poder de ordem simbólica, tendo no processo educativo a sua mola propulsora, que corresponde à disposição aberta no exame da realidade e no direito à liberdade de expressão, distinta do descaso predominante hoje.

Uma discussão sobre o filme Extraordinário serviu de pretexto pedagógico para desenvolver a discussão criadora e o assunto da barbárie, violência e desumanização em sala de aula, adentrando nas diferentes possibilidades contidas nesse recurso, uma ficção com ideologias ocultas ou um registro da realidade. A cinematografia evidencia paradoxos que podem ser ressignificados pelos educadores e estudantes na conversação, quanto coincidem com uma cultura massificada e desumanizada em todas as esferas sociais. Sem dúvida, a cinematografia tem forte influência nas formas de pensar o mundo, que acaba alimentando ideias revolucionárias e visionárias com o poder de denunciar pelo gesto ou por pressupostos idealizadores (sob condições inviáveis), assim como traz repercussões de comportamentos com traços desagregadores e de desumanização.

\section{Referências}

ADORNO, Theodor Ludwig Wiesengrund. Educação e emancipação. 3. ed. Rio de Janeiro: Paz e Terra, 1995.

ADORNO, Theodor Ludwig Wiesengrund; HORKHEIMER, Max. A Dialética do Esclarecimento. Rio de Janeiro: Jorge Zahar, 1985.

ADORNO, Theodor Ludwig Wiesengrund. Teoria da Semicultura. Trad. Newton Ramosde-Oliveira. Educação e Sociedade, Campinas, ano VII, n. 56, p. 388-411, dez. 1996.

BENJAMIN, Walter. Magia e técnica, arte e politica: ensaios sobre literatura e história da cultura. São Paulo: Brasiliense, 1994.

BOURDIEU, Pierre. O poder simbólico. Lisboa: Difel, 1989.

CHARLOT, Bernard. Da relaşão com o saber às práticas educativas. São Paulo: Cortez, 2013.

CHARLOT, Bernard. A questão antropológica na Educação quando o tempo da barbárie está de volta. Educar em Revista, Curitiba, v. 35, n. 73, p. 161-180, jan./fev. 2019. Disponível em: < https://revistas.ufpr.br/educar/article/view/62350/37913> Acesso em: 05 abr. 2019. 
FREUD, Sigmund. Mal-estar na civilização. Obras psicológicas completas de Sigmund Freud. Vol: XXI. Rio de Janeiro: Imago, 1930.

HABERMAS, Jürgen. O discurso filosófico da modernidade. Lisboa: Dom Quixote, 1990.

HABERMAS, Jürgen. Agir comunicativo e razão destranscendentalizada. Trad. Lucia Aragão. Rio de Janeiro: Tempo Brasileiro, 2002.

HABOWSKI, Adilson Cristiano; CONTE Elaine; BRANCO, Lilian Soares Alves. A violência institucionalizada pela Indústria Cultural: debates educativos. Revista Internacional de Educação Superior, Campinas, v. 4, n. 2, p. 481-498, 2018. Disponível em:

$<$ https://periodicos.sbu.unicamp.br/ojs/index.php/riesup/article/view/8651336/17625> Acesso em: 18 fev. 2019.

HABOWSKI, Adilson Cristiano; CONTE Elaine; FLORES, Helen Rose Flores de. Educação e violência na teoria crítica de Adorno. Fragmentos de cultura, Goiânia, v. 28, n. 2, p. 231-245, jan./mar. 2018. Disponível em:

<http://revistas.pucgoias.edu.br/index.php/fragmentos/article/view/6440/3768> Acesso em: 02 abr. 2019.

HORKHEIMER, Max. Teoria Tradicional e Teoria Crítica. In: BENJAMIN, W.; HORKHEIMER, M.; ADORNO, T.; HABERMAS, J. Textos Escolbidos. São Paulo: Abril Cultural, 1991. p. 31-68.

LOUREIRO, Robson. Educação, cinema e estética: elementos para uma reeducação do olhar. Educação e Realidade, Porto Alegre, v. 33, n. 1, p. 135-154, 2008. Disponível em: < http://seer.ufrgs.br/educacaoerealidade/article/view/6691>. Acesso em: 16 jan. 2019.

MORETTIN, Eduardo Victorio. O cinema como fonte histórica na obra de Marc Ferro. In: CAPELATO. M. H. et al. História e cinema. São Paulo: Alameda. 2007. pp. 39-64.

Recebido em: 15 abr. 2019 / Aprovado em: 25 jun. 2019

\section{$\underline{\text { Cite como }}$}

HABOWSKI, Adilson Cristiano; CONTE, Elaine; NEVES NETO, Raul Maia de Andrade. Violência e educação: sensibilização por meio da cinematografia. Dialogia, São Paulo, n. 32, p. 52-64, maio/ago. 2019. Disponível em: https://doi.org/10.5585/Dialogia.n32.13614. 